\section{THU0393 PERFORMANCE OF THE ASAS CLASSIFICATION CRITERIA PRESENTING WITH UNDIAGNOSED BACK PAIN? DATA FROM THE SCREENING IN AXIAL SPONDYLOARTHRITIS IN PSORIASIS, IRITIS, AND COLITIS (SASPIC) COHORT}

Walter P Maksymowych ${ }^{1,2}$, Raj Carmona ${ }^{3}$, James Yeung ${ }^{4}$, Jon Chan ${ }^{5}$, Liam Martin $^{6}$, Sibel Aydin ${ }^{7}$, Dianne Mosher ${ }^{6}$, Ariel Masetto ${ }^{8}$, Stephanie Keeling ${ }^{1}$, Olga Ziouzina ${ }^{6}$, Sherry Rohekar ${ }^{9}$, Joel Paschke ${ }^{2}$, Amanda Carapellucci' ${ }^{2}$, Robert G Lambert ${ }^{1} .{ }^{1}$ University of Alberta, Edmonton, Canada; ${ }^{2}$ CaRE Arthritis, Edmonton, Canada; ${ }^{3}$ McMaster University, Hamilton, Canada; ${ }^{4}$ James Yeung Rheumatology, Vancouver, Canada; ${ }^{5}$ Artus Health Center, Edmonton, Canada; ${ }^{6}$ University of Calgary, Calgary, Canada; ${ }^{7}$ University of Ottawa, Ottawa, Canada; ${ }^{8}$ University of Sherbrooke, Sherbrooke, Canada; ${ }^{9}$ Lawson Health Research Institute, London, Canada

Background: Classification criteria for axial spondyloarthritis (axSpA) that capture the spectrum of disease present challenges due to the frequency of back pain, the relative infrequency of $\operatorname{axSpA}$, and limited physical and laboratory findings in early disease. Several cohorts have reported the performance of the ASAS classification criteria in settings where patients have been selected for certain features such as the presence of inflammatory back pain and/or short symptom duration.

Objectives: We aimed to test the performance of the ASAS classification criteria in unselected patients referred with undiagnosed back pain who have presented with acute anterior uveitis (AAU), psoriasis, or colitis to their respective specialists and whether performance varied according to demographic factors and symptom severity.

Methods: he multicenter Screening for Axial Spondyloarthritis in Psoriasis, Iritis, and Colitis (SASPIC) Study is aimed at early detection of axial SpA. Consecutive patients $\leq 45$ years of age with $\geq 3$ months undiagnosed back pain with any one of psoriasis, acute anterior uveitis (AAU), or colitis undergo routine clinical evaluation by a rheumatologist for axial SpA and MRI evaluation is ordered per rheumatologist decision. The rheumatologist determines the presence or absence of axial $\mathrm{SpA}$ and the degree of confidence in the diagnosis ( -10 (definitely not $\mathrm{SpA}$ ) to +10 (definite $\mathrm{SpA}$ )) at 3 consecutive stages: 1 . After the clinical evaluation; 2. After the results of labs (B27, CRP) and radiography; 3 . After the results of MRI evaluation. Assessment of imaging was conducted by local and central readers. We calculated the sensitivity and specificity of the ASAS criteria and the component imaging and clinical arms using the stage 3 diagnostic assessment by the local rheumatologist as gold standard.

Results: A total of 246 patients were recruited, $47.6 \%$ being diagnosed with axSpA $(61.5 \%$ male, age 33.7 years, symptom duration 7.6 years, B27 positive $52.1 \%$ ), after stage 3 evaluation. Sensitivity/specificity of the ASAS criteria, imaging arm, clinical arm were 74.4/79.8\%, 55.6/93.8\%, $50.4 / 82.2 \%$, respectively (Table). For patients diagnosed with a high degree of confidence sensitivity/specificity was $87.5 / 82.7 \%, 68.8 / 94.5 \%$, $56.3 / 84.5 \%$, respectively. Specificity, especially for the clinical arm, was notably higher in patients with a higher degree of back pain $(\geq 5 / 10)$, and in those with longer symptom duration ( $\geq 5$ years).

Abstract THU0393 -Table 1

\begin{tabular}{|c|c|c|c|c|c|c|c|}
\hline \multirow[t]{2}{*}{ Patient Category } & \multirow[t]{2}{*}{ Number } & \multicolumn{2}{|c|}{$\begin{array}{l}\text { ASAS } \\
\text { criteria }\end{array}$} & \multicolumn{2}{|c|}{ Imaging arm } & \multicolumn{2}{|c|}{ Clinical arm } \\
\hline & & $\overline{\text { Sen }}$ & Spec & Sen & Spec & Sens & Spec \\
\hline All patients & 246 & 74.4 & 79.8 & 55.6 & 93.8 & 50.4 & 82.2 \\
\hline $\begin{array}{l}\text { Patients diagnosed with } \\
\text { confidence }>7 \text { for axSpA yes } \\
\text { and }<-4 \text { for not axSpA (-10 to } \\
+10 \text { scale) }\end{array}$ & 190 & 87.5 & 82.7 & 68.8 & 94.5 & 56.3 & 84.5 \\
\hline $\begin{array}{l}\text { Patients with back pain } \geq 5 \text { (0- } \\
10 \text { scale) }\end{array}$ & 165 & 74.7 & 83.7 & 54.4 & 94.2 & 51.9 & 84.9 \\
\hline $\begin{array}{l}\text { Patients with back pain }<5 \text { ( } 0 \text { - } \\
10 \text { scale) }\end{array}$ & 81 & 73.7 & 72.1 & 57.9 & 93.0 & 47.4 & 76.7 \\
\hline $\begin{array}{l}\text { Patients with symptom } \\
\text { duration } \geq 5 \text { years }\end{array}$ & 143 & 78.1 & 85.7 & 53.4 & 95.7 & 56.2 & 85.7 \\
\hline $\begin{array}{l}\text { Patients with symptom } \\
\text { duration }<5 \text { years }\end{array}$ & 103 & 68.2 & 72.9 & 59.1 & 91.5 & 40.9 & 78.0 \\
\hline Males & 129 & 73.6 & 78.9 & 61.1 & 89.5 & 48.6 & 84.2 \\
\hline Females & 117 & 75.6 & 80.6 & 46.7 & 97.2 & 53.3 & 80.6 \\
\hline
\end{tabular}

Conclusion: The performance of the ASAS criteria in the SASPIC cohort is comparable to the findings in the original ASAS classification study. Performance may vary according to symptom duration and severity of symptoms which likely impacts diagnostic ascertainment.

Disclosure of Interests: Walter P Maksymowych Grant/research support from: AbbVie, Pfizer, Janssen, Novartis, Consultant for: AbbVie, Eli Lilly,
Boehringer, Galapagos, Janssen, Novartis, Pfizer and UCB Pharma; Chief Medical Officer for Canadian Research and Education Arthritis, Raj Carmona Grant/research support from: Amgen, Abbvie, Jannsen, Consultant for: Amgen, Abbvie, BMS, Eli Lilly, Merck, Novartis, Jannsen, Takeda, UCB, James Yeung: None declared, Jon Chan Grant/research suppor from: Janssen, UCB, Novartis, Pfizer, Celgene, Consultant for: Amgen, Celgene, Eli Lilly, Janssen, Amgen, Abbvie, Novartis, Pfizer, UCB, Sandoz, Merck, Liam Martin: None declared, Sibel Aydin Consultant for: Abbvie, Celgene, UCB, Novartis, Jannsen, Sanofi, Dianne Mosher: None declared, Ariel Masetto Grant/research support from: Amgen, Sanofi, Consultant for: Sanofi, Pfizer, Bristol-Myers Squibb, Novartis, Boehringer Ingelheim, Speakers bureau: Novartis, Stephanie Keeling Consultant for AbbVie. Pfizer, Eli Lily, Janssen, Amgen, Astrzeeneca, UCB., Olga Ziouzina: None declared, Sherry Rohekar Consultant for: Abbvie, Amgen, BMS, Celgene, Eli-Lilly, Janssen, Merck, Novartis, Pfizer, Roche, Sanofi, UCB, Joel Paschke: None declared, Amanda Carapellucci: None declared, Robert G Lambert Consultant for: Bioclinica, Parexel, Abbvie

DOI: 10.1136/annrheumdis-2019-eular.6354

\section{THU0394 THE PREVALENCE OF EXTRA-ARTICULAR MANIFESTATIONS IN AXIAL SPONDYLOARTHRITIS AND PSORIATIC ARTHRITIS IS ASSOCIATED TO DISEASE DURATION: RESULTS FROM THE LEEDS SPECIALIST SPONDYLOARTHRITIS SERVICE}

Xabier Michelena-Vegas ${ }^{1,2}$, Sayam Dubash ${ }^{1}$, Ann Morgan ${ }^{1}$, Helena MarzoOrtega ${ }^{1} .{ }^{1}$ NIHR Leeds Biomedical Research Centre, Leeds Teaching Hospitals Trust, LIRRM and LICAM, University of Leeds, Leeds, United Kingdom; ${ }^{2}$ Bellvitge University Hospital (IDIBELL), Barcelona, Spain

Background: Psoriasis, uveitis and inflammatory bowel disease (IBD) are extra-articular manifestations (EAMs) that can occur in both axial Spondyloarthritis (axSpA) and psoriatic arthritis ( $P s A)$. Their prevalence has been outlined independently in a recent meta-analysis ${ }^{1}$ for axSpA and in several series in PsA with variable results. Although the diagnostic delay of inflammatory arthritis has been reduced in the last years, it remains a significant unmet need, particularly in axSpA. There are limited data on the relationship between diagnostic delay and the appearance of EAMs. Objectives: To explore the prevalence of EAMs in a cohort of axSpA and PsA patients, and its relationship to disease duration and possible diagnostic delay in both groups.

Methods: Cross-sectional, single centre, observational cohort study of consecutive patients attending a large tertiary specialist clinic. All subjects provided written consent (2005-2018). Only patients fulfilling the modified New York (mNY) criteria for ankylosing spondylitis and CASPAR criteria for PsA were considered for this analysis. Demographic and clinical data were retrieved during enrolment and cross-referenced with the clinical notes. To explore the relationship between presence of EAMs, disease duration and delay to diagnosis, only uveitis and IBD were considered because of psoriasis being common in the PsA group. Univariate (Mann Whitney U-test) and multivariate analysis (binary logistic regression) with variables of sex, age, disease duration and diagnostic delay were performed.

Results: Data from 988 patients were available for analysis $(n=418$ axSpA, $n=570$ PsA). Demographic and clinical characteristics are summarised in Table 1.

In the axSpA group, 187 cases (44.7\%) presented with EAMs (including psoriasis) and $67(16.02 \%)$ of these had more than 1 EAM. In the PsA group, 32 cases $(5.6 \%)$ presented with EAM (excluding psoriasis) and only 3 cases $(0.5 \%)$ had more than one EAM.

In the PsA group, a median delay of 4 years (IQR 2-9) was observed between psoriasis onset and PsA. In 42 cases the psoriasis appeared after the PsA onset. The predominant PsA phenotype was polyarticular $(n=298 ; 52.3 \%)$ of which $n=118,20.7 \%$ had erosive disease. $101(17.7 \%)$ had a predominantly axial phenotype.

Disease duration and delay to diagnosis were longer in the axSpA group $(p<0.0001)$. Further univariate analysis showed an association between disease duration and the presence of EAMs when analysing the whole cohort $(p<0.001)$ and the axSpA group $(p<0.001)$, but not in the PsA group $(p=0.832)$. The diagnostic delay was associated to the presence of EAMs in the whole cohort $(p<0.001)$, but not in the individual disease groups. In the multivariate analysis only disease duration was related to presence of EAMs in the whole cohort (OR 1.064 95\% IC 1.044-1.086) and axSpA group (OR 1.043 95\%IC 1.016-1.070). 